\title{
Regulation of Glucose Control in People with Type 2 Diabetes: A Review and Consensus
}

\begin{abstract}
Jeong-Taek Woo ${ }^{1}$, Kyung Soo Park ${ }^{2}$, Dong-Won Byun ${ }^{3}$, Kyung Soo Ko ${ }^{4}$, Yoon-Sok Chung 5 , Doo Man Kim ${ }^{6}$, Tae Sun Park Bong Soo Cha ${ }^{8}$, In Kyu Lee, Joong Yeol Park ${ }^{10}$, Hyun Shik Son ${ }^{11}$, Moon-Kyu Lee ${ }^{12}$, Kwang Won Kim ${ }^{13}$, Ho Young Son ${ }^{14}$

${ }^{1}$ Discussant and author of manuscript (The opinions of members of the committee on the treatment of diabetes mellitus, Korean Diabetes Association were collected in the manuscript writing.), Chairman of the Committee on the Treatment of Diabetes Mellitus, Korean Diabetes Association, Kyung Hee University School of Medicine, ${ }^{2}$ Organizer and discussant, Director of the Science and Research Committee, Korean Endocrine Society, Seoul National University College of Medicine, ${ }^{3}$ Discussant, Chairman of the Special Committee for Consensus Position Statement, Korean Endocrine Society, Soonchunhyang University College of Medicine, ${ }^{4}$ Discussant, Secretary General, Korean Diabetes Association, Inje University College of Medicine, ${ }^{5}$ Discussant, Secretary General, Korean Endocrine Society, Ajou University School of Medicine, ${ }^{6}$ Speaker and discussant, Chairman of the Committee of Education, Korean Diabetes Association, Hallym University College of Medicine, ${ }^{7}$ Speaker and discussant, Chairman of the Committee of Drug and Health Insurance, Korean Diabetes Association, Chonbuk National University Medical School, ${ }^{8}$ Speaker and discussant, Chairman of the Committee of Public Relation, Korean Diabetes Association, Yonsei University College of Medicine, 'Speaker and discussant, Chairman of the Committee of Research, Korean Diabetes Association, Kyungpook National University School of Medicine, ${ }^{10}$ Discussant, Secretary Treasure, Korean Diabetes Association, University of Ulsan College of Medicine, ${ }^{11}$ Discussant, Chairman of the Committee of Publication, Korean Diabetes Association, The Catholic University of Korea, School of Medicine, ${ }^{12}$ Discussant, Chairman of International Liason Committee, Korean Diabetes Association, Sungkyunkwan University School of Medicine, ${ }^{13}$ Chairman, President of Korean Society for the Study of Obesity, Sungkyunkwan University School of Medicine, ${ }^{14}$ Chairman, President of Korean Endocrine Society, The Catholic University of Korea School of Medicine
\end{abstract}

A conference was convened by the Korean Diabetes Association and the Korean Endocrine Society on September 7, 2009 to discuss and organize the results of research on intensive glucose control for the prevention of cardiovascular disease in patients with type 2 diabetes. Professor Kyung Soo Park led the conference, and Professors Kwang Won Kim and Ho Young Son acted as chairmen. Professors Doo Man Kim, Tae Sun Park, and Bong Soo Cha reported on intensive glucose control and diabetic complications, including the UK Prospective Diabetes Study (UKPDS), Diabetes Control and Complication Trial (DCCT) research results, the recently published Action to Control Cardiovascular Risk in Diabetes (ACCORD), Action in Diabetes and Vascular Disease: Preterax and Diamicron Modified Release Controlled Evaluation (ADVANCE), and Veterans Affairs Diabetes Trial (VADT) research, as well as meta-analyses. Professor Jeong-Taek Woo reported on the manuscript written by the committee for the Korean Diabetes Association which dealt with the treatment of diabetes mellitus. Professors Kyung Soo Ko, Joong Yeol Park, Hyun Shik Son, Moon-Kyu Lee, Dong-Won Byun, and Yoon-Sok Chung participated in the discussion and collected information for the manuscript from all of the participants. The aim of the debate was to determine how to establish target goals for intensive glucose control and how to individualize those goals. The participants concluded that there was no need to modify the recommendation of maintaining an $\mathrm{HbAlc}$ under 6.5\%, the current blood glucose treatment goal that is recommended by the Korean Diabetes Association. In addition, individual target goals for glucose control were recommended depending on the situation of each patient. We report on the consensus statement from the meeting.

\section{INTRODUCTION}

The pathogenesis of type 2 diabetes is characterized by increased insulin resistance and decreased insulin secretion. An increase in insulin secretion occurs in an attempt to maintain proper glucose metabolism by overcoming the insulin resistance in people with normal glucose tolerance. Type 2 diabetes occurs as a result of progressive pancreatic $\beta$-cell dysfunction that disturbs normal glucose metabolism.

In addition to elevated blood glucose levels, patients with
Corresponding author: Jeong-Taek Woo

Department of Endocrinology and Metabolism, Kyung Hee University

Medical Center, Hoegi-dong, Dongdaemun-gu, Seoul 130-702, Korea E-mail: jtwoomd@khmc.or.kr

${ }^{*}$ A review of recent research by the Korean Diabetes Association and the Korean Endocrine Society regarding intensive glucose control and the prevention of cardiovascular diseases.
This is an Open Access article distributed under the terms of the Creative Commons Attribution Non-Commercial License (http://creativecommons.org/licenses/by-nc/3.0/) which permits unrestricted non-commercial use, distribution, and reproduction in any medium, provided the original work is properly cited.

Copyright @ 2010 Korean Diabetes Association

www.e-kdj.org 
type 2 diabetes frequently suffer from several additional conditions such as obesity and other features of metabolic syndrome. Therefore, the risk of macrovascular as well as microvascular complications should be added to the cardiovascular risk factors that are associated with high blood glucose level. Results from the UK Prospective Diabetes Study (UKPDS) [1] showed that newly diagnosed patients with type 2 diabetes who received intensive glucose control for ten years (HbA1c mean value, $7 \%$ ) had a $25 \%$ decreased risk of microvascular complications compared to patients who received conventional treatment (7.9\%). Because HbAlc and the risk of microvascular complications have a linear relationship, the American Diabetes Association [2] set the goal of glycemic control to be below an $\mathrm{HbAlc}$ of 7\%. The Korean Diabetes Association [3] set the target $\mathrm{HbA1c}$ below $6.5 \%$ based on the Kumamoto research [4] results in Japan. However, the beneficial effects of intensive glycemic control on great vessel disease, especially cardiovascular disease, are unclear. According to the UKPDS, intensive glycemic treatment showed only a slight benefit for the prevention of cardiovascular disease $(16 \%$ decrease; $P=$ 0.052).

About ten years ago, following the UKPDS report, additional studies were planned to determine whether intensive glucose control in patients with type 2 diabetes (who had a relatively high risk of cardiovascular disease) reduced the occurrence of cardiovascular disease. The results of these studies were recently published [5-8] and showed contradictory results. In one study, mortality was increased in the intensive glucose control group [5]. The Korean Diabetes Association and the Korean Endocrine Society thought that the medical literature on this topic would be confusing to readers. Therefore, a meeting was organized to discuss the literature and to provide a consensus statement regarding the studies and their results.

\section{SUMMARY OF THE RECENT RESEARCH RESULTS}

\section{Action to Control Cardiovascular Risk in Diabetes (ACCORD) study [5]}

The purpose of this study was to determine whether cardiovascular disease was prevented when blood glucose was maintained at normal levels in patients with type 2 diabetes who also suffered from cardiovascular disease or had risk factors for cardiovascular disease. 10,251 patients with a mean age of
62.2 years (baseline $\mathrm{HbAlc}$ median value, $8.3 \%$ ) were followed for four to eight years (average 5.6 years). These patients received either comprehensive intensive therapy with an $\mathrm{HbAlc}$ target of less than $6.0 \%$ or standard therapy with a target HbAlc of $7.0 \%$ to $7.9 \%$. However, a higher mortality rate in the intensive therapy group led to the discontinuation of the research after a mean follow-up period of 3.5 years. After one year, stable median $\mathrm{HbAlc}$ levels of $6.4 \%$ and $7.5 \%$ were achieved in the intensive-therapy group and the standardtherapy group, respectively. There were no statistical differences in the primary outcomes between the two groups. However, 257 patients in the intensive treatment group and 203 in the standard treatment group died during the study (hazard ratio, 1.22 ; $95 \%$ confidence interval $[\mathrm{CI}], 1.01$ to $1.46 ; P=0.04$ ), resulting in a significantly increased mortality rate in the intensive therapy group. As a result, these findings raised the possibility of a previously unrecognized risk associated with intensive glucose lowering in high-risk patients who have type $2 \mathrm{di}$ abetes.

Primary outcome: a composite of non-fatal myocardial infarction, non-fatal stroke, or death from cardiovascular causes.

\section{Action in Diabetes and Vascular Disease: Preterax and Diamicron Modified Release Controlled Evaluation (ADVANCE) study [6]}

This study was carried out with the same goal as that of the ACCORD study. It was different from the ACCORD study in that the target $\mathrm{HbA1c}$ goal was set below $6.5 \%$ for the intensive therapy group, gliclazide (modified release) was chosen as the basic treatment, and additional medication was added depending on need. A total of 11,140 patients with type 2 diabetes and a mean age of 66 were included in the study. The median $\mathrm{HbAlc}$ concentration before the start of the study was $7.2 \%$. The median follow-up period was five years. The median $\mathrm{HbAlc}$ concentration after five years was $6.5 \%$ in the intensive treatment group and $7.3 \%$ in the standard treatment group. The intensive treatment group showed a $10 \%$ reduction in the incidence of the primary outcome ( $18.1 \%$ vs. $20.0 \%$; hazard ratio, 0.90 ; $95 \%$ CI, 0.82 to $0.98 ; P=0.01$ ). These results were primarily due to a reduction in the incidence of nephropathy. There were no statistical differences between the two groups in regard to major macrovascular events, deaths from cardiovascular causes, or deaths from any other cause.

Primary outcome: a composite of major macrovascular events (death from cardiovascular causes, non-fatal myocardial infarc- 
tion, or non-fatal stroke) and major microvascular events (new or worsening nephropathy or retinopathy).

\section{Veterans Affairs Diabetes Trial (VADT) [7]}

This study enrolled 1,792 patients who had type 2 diabetes. They had an average age of 60.4 years, and $97 \%$ of the patients were male. The study population was randomly divided into intensive and standard treatment groups. The average HbAlc concentration at the start of the study was 9.4\%. After an average follow-up period of 5.6 years, the HbA1c values dropped to an average of $6.0 \%$ in the intensive treatment group and to $8.4 \%$ in the standard treatment group. There were no statistically significant differences between the two groups in the primary outcome measurements or death rates from all causes. In addition, there were no differences in microvascular complications between the two groups.

Primary outcome: The time from randomization to the first occurrence of a major cardiovascular event. A major cardiovascular event was defined as a myocardial infarction, stroke, death from cardiovascular causes, congestive heart failure, surgery for vascular disease, inoperable coronary disease, or amputation due to ischemic gangrene.

\section{Effect of intensive control of glucose on cardiovascular} outcomes and death in patients with type 2 diabetes: a meta-analysis of randomized controlled trials [9]

According to the results mentioned above, the American Heart Association, the American College of Cardiology, and the American Diabetes Association set the preventive effects of glycemic control for cardiovascular diseases as a Class IIb recommendation. However, individual studies have shown that the control of risk factors associated with cardiovascular disease has improved. The results showed a reduced incidence of cardiovascular disease. The treatment period was too short and the differences in glycemic control were too small to expect sufficient beneficial effects. Ray et al. [9] assessed the effects of intensive glucose control using a meta-analysis. Five studies (UKPDS [1], PROactive [10], ADVANCE [6], VADT [7], ACCORD [5]) were chosen for inclusion in the review. After analyzing 33,040 patients, intensive glycemic control ( $0.9 \%$ drop in $\mathrm{HbAlc}$ levels for five years) was found to reduce the rate of non-fatal myocardial infarctions by $17 \%$ (odds ratio, $0.83 ; 95 \%$ CI, 0.75 to 0.93$)$ and that of coronary heart disease by $15 \%(0.85$; 0.77 to 0.93$)$. However, it did not decrease the death rates due to stroke or any other causes of mortality.

\section{THE REASON FOR INCREASED MORTALITY IN THE GROUP WITH INTENSIVE GLUCOSE CONTROL IN THE ACCORD STUDY}

The increased mortality observed in the ACCORD study was likely due to the frequency of significant hypoglycemic events, the significant increase in the use of insulin or thiazolidinediones and drug combinations, as well as weight gain. However, these explanations require confirmation. Significant hypoglycemia may increase the risk of cardiovascular disease due to subclinical cardiovascular autonomic dysfunction in patients who are at high risk for cardiovascular disease. This could increase the risk of sudden death. Because glucose was tightly controlled in the intensive treatment group, the complex combination of stress, an unknown impact of the drugs used in combination with insulin and their frequent modifications, and weight gain may have contributed to the outcome.

The death rate did not increase in the ADVANCE study despite a similar intensive glucose control. The average patient in the ADVANCE study had diabetes for eight years, two years less than the average patient in the ACCORD study. The median $\mathrm{HbAlc}$ level was $7.2 \%$ at the start of the study. This was lower than that of the ACCORD study (8.1\%). The blood glucose was gradually lowered after the study began, and the weight gain was not significant. The incidence of severe hypoglycemia was less than $3 \%$ over five years. This was relatively low compared to that of the ACCORD (16\%) and the VADT studies (21\%). Therefore, it is possible that the increased mortality seen in the intensive treatment group of the ACCORD study could have been due to the treatment strategy used for lowering blood glucose.

\section{RECOMMENDATIONS FOR CLINICAL MANAGEMENT}

It is beneficial for people who have diabetes (type 1 or type 2) to control their blood glucose so that it is as close to normal as possible. Large studies [5-8] have shown that intensive glycemic control does not prevent cardiovascular disease, the most significant cause of death associated with type 2 diabetes. However, this does not reduce the significance of intensive glycemic control. In addition to treatments for other cardiovascular disease risk factors (including the use of anti-hypertensive medications and statins), the effects of intensive glycemic control were too small to show any clinical benefit with regard to car- 
diovascular disease. There was no reduction in the frequency of myocardial infarctions in the intensive glycemic control group of the UKPDS study. However, an extension of the initial randomized groups in the UKPDS study showed a reduction in the frequency of myocardial infarctions and all-cause mortality with intensive glucose control [11]. Therefore, the clinical benefits of intensive glycemic control cannot be observed over a relatively short period of time.

Improved outcomes require both drug treatment and lifestyle modifications for most people who have type 2 diabetes. However, most people with type 2 diabetes depend on drug treatment because lifestyle changes are harder to implement. Blood glucose-lowering drugs have side effects in addition to their beneficial effects of reducing the blood glucose levels. The longer a person has diabetes, the greater is the likelihood that they will require an increased number of drugs and therefore have an increased risk of experiencing these side effects. Because of this, it is hard to reach a consensus on treatment. A compromise on treatment methods must be reached based on the medical and ethical situation of each individual patient. Complete knowledge of the patient's condition is required in order to make the best judgment.

Currently, the Korean Diabetes Association does not recommend changing the blood glucose treatment goal below an $\mathrm{HbA1c}$ of $6.5 \%$. This is the target recommended by the existing guidelines [4] for the prevention of diabetic complications. However, considering the results of the studies discussed above and the goal of individualizing care for diabetic patients, the following recommendations are suggested.

1) For newly diagnosed people with type 2 diabetes, intensive glucose control is required during the early stage. Only patients who have cardiovascular disease or those who are at high risk for cardiovascular disease require individually established goals for blood glucose values. Active management of other cardiovascular risk factors (such as smoking, sedentary life style, poor eating habits, dyslipidemia, and hypertension) is also required.

2) Intensive glucose control is also required for people with type 2 diabetes who are already being treated. Only patients who have cardiovascular disease or those who are at high risk for cardiovascular disease require individually established goals for blood glucose values. Blood glucose levels should be gradually decreased in order to prevent a large variability of blood glucose by diabetic drug treatments.
Active management of other cardiovascular risk factors (such as smoking, sedentary life style, poor eating habits, dyslipidemia, and hypertension) is also required.

\section{THE CONCLUSIONS FROM THESE RECENT STUDIES}

Based on the results of recent studies which examined outcome results by setting specific goals for low-density lipoprotein cholesterol (ENHANCE) [12], high-density lipoprotein cholesterol (ILLUMINATE) [13], blood pressure (ONTARGET) [14], and HbAlc (ACCORD) [5] in order to prevent the occurrence of cardiovascular disease in high risk patients, including people with type 2 diabetes, it became clear that it is not important only to reach specific goals for these cardiovascular disease risk factors. However, different outcomes can be obtained depending on the method that is used to reach the target. The treatment guidelines have been developed based on the data that has been gathered to so far. Most analyses of these study results are based on determining whether or not the risk factor goals have been reached, without considering the quality of the treatments. It is necessary to evaluate the treatment method in terms of clinical benefits and risks in order to determine the possible overall clinical outcomes, including an improvement in the quality of life and prevention of complications.

\section{ACKNOWLEDGEMENT}

None of authors has any conflict of interest concerning this manuscript.

\section{REFERENCES}

1. UK Prospective Diabetes Study (UKPDS) Group. Intensive blood-glucose control with sulphonylureas or insulin compared with conventional treatment and risk of complications in patients with type 2 diabetes (UKPDS 33). Lancet 1998;352: 837-53.

2. American Diabetes Association. Standards of medical care in diabetes - 2009. Diabetes Care 2009;32 Suppl 1:S13-61.

3. Korean Diabetes Association. Clinical practice guideline, Seoul: MM Communications; 2007. p. 40-42.

4. Ohkubo Y, Kishikawa H, Araki E, Miyata T, Isami S, Motoyoshi S, Kojima Y, Furuyoshi N, Shichiri M. Intensive insulin thera- 
py prevents the progression of diabetic microvascular complications in Japanese patients with non-insulin-dependent diabetes mellitus: a randomized prospective 6-year study. Diabetes Res Clin Pract 1995;28:103-17.

5. Action to Control Cardiovascular Risk in Diabetes Study Group, Gerstein HC, Miller ME, Byington RP, Goff DC Jr, Bigger JT, Buse JB, Cushman WC, Genuth S, Ismail-Beigi F, Grimm RH Jr, Probstfield JL, Simons-Morton DG, Friedewald WT. Effects of intensive glucose lowering in type 2 diabetes. $\mathrm{N}$ Engl J Med 2008;358:2545-59.

6. ADVANCE Collaborative Group, Patel A, MacMahon S, Chalmers J, Neal B, Billot L, Woodward M, Marre M, Cooper M, Glasziou P, Grobbee D, Hamet P, Harrap S, Heller S, Liu L, Mancia G, Mogensen CE, Pan C, Poulter N, Rodgers A, Williams B, Bompoint S, de Galan BE, Joshi R, Travert F. Intensive blood glucose control and vascular outcomes in patients with type 2 diabetes. N Engl J Med 2008;358:2560-72.

7. Duckworth W, Abraira C, Moritz T, Reda D, Emanuele N, Reaven PD, Zieve FJ, Marks J, Davis SN, Hayward R, Warren SR, Goldman S, McCarren M, Vitek ME, Henderson WG, Huang GD; VADT Investigators. Glucose control and vascular complications in veterans with type 2 diabetes. N Engl J Med 2009; 360:129-39.

8. Holman RR, Paul SK, Bethel MA, Matthews DR, Neil HA. 10year follow-up of intensive glucose control in type 2 diabetes. N Engl J Med 2008;359:1577-89.

9. Ray KK, Seshasai SR, Wijesuriya S, Sivakumaran R, Nethercott S, Preiss D, Erqou S, Sattar N. Effect of intensive control of glucose on cardiovascular outcomes and death in patients with diabetes mellitus: a meta-analysis of randomised controlled trials. Lancet 2009;373:1765-72.

10. Dormandy JA, Charbonnel B, Eckland DJ, Erdmann E, MassiBenedetti M, Moules IK, Skene AM, Tan MH, Lefèbvre PJ, Murray GD, Standl E, Wilcox RG, Wilhelmsen L, Betteridge J, Birkeland K, Golay A, Heine R, Korányi L, Laakso M, Mokán M, Norkus A, Pirags V, Podar T, Scheen A, Scherbaum W, Schernthaner G, Schmitz O, Skrha J, Smith U, Taton J; PROactive investigators. Secondary prevention of macrovascular events in patients with type 2 diabetes in the PROactive Study (PROspective pioglitAzone Clinical Trial In macroVascular Events): a randomised controlled trial. Lancet 2005;366:1279-89.

11. Holman RR, Paul SK, Bethel MA, Neil HA, Matthews DR. Longterm follow-up after tight control of blood pressure in type 2 diabetes. N Engl J Med 2008;359:1565-76.

12. Kastelein JJ, Akdim F, Stroes ES, Zwinderman AH, Bots ML, Stalenhoef AF, Visseren FL, Sijbrands EJ, Trip MD, Stein EA, Gaudet D, Duivenvoorden R, Veltri EP, Marais AD, de Groot E; ENHANCE Investigators. Simvastatin with or without ezetimibe in familial hypercholesterolemia. N Engl J Med 2008;358:143143.

13. Barter PJ, Caulfield M, Eriksson M, Grundy SM, Kastelein JJ, Komajda M, Lopez-Sendon J, Mosca L, Tardif JC, Waters DD, Shear CL, Revkin JH, Buhr KA, Fisher MR, Tall AR, Brewer B; ILLUMINATE Investigators. Effects of torcetrapib in patients at high risk for coronary events. N Engl J Med 2007;357:210922.

14. ONTARGET Investigators, Yusuf S, Teo KK, Pogue J, Dyal L, Copland I, Schumacher H, Dagenais G, Sleight P, Anderson C. Telmisartan, ramipril, or both in patients at high risk for vascular events. N Engl J Med 2008;358:1547-59. 